\title{
Algorytmy wyboru dróg przewozu ladunków w transporcie kolejowym
}

\begin{abstract}
W pracy przedstawiono przybliżone algorytmy wyboru marszrut dla potoków tadunków $w$ transporcie kolejowym. Bazuja one na sieciach zrównoważonych $i$ wykorzystuja cykle o wagach ujemnych z cyrkulacja potoków. Wykorzystanie metod linearyzacji stycznymi $i$ cięciwami znacznie zwiększyło efektywność zaproponowanych algorytmów.
\end{abstract}

Przewozy transportem kolejowym, w odróżnieniu od przewozów innymi gałęziami transportu, dopuszczających rozdzielenie potoku ładunków, charakteryzuja się wysokim stopniem koncentracji, w którym ograniczenia dotyczące niepodzielności przesyłki odgrywają rolę pierwszoplanową.

Zatem, zadanie wyboru marszruty, w którym korespondencja nie może być rozdzielana na różne drogi, staje się nowym i pojawia się konieczność opracowania efektywnego algorytmu jego rozwiązania.

Budowany poniżej algorytm uwzględnia zarówno podzielność, jak i nie podzielność potoku ładunków.

W przypadku pierwszym można wykorzystać podejście oparte na metodzie gradientowej, która przewiduje stopniowy rozkład macierzy korespondencji $\left\|N_{i j}\right\|$. W każdym $[n]$ - tym kroku następuje dodatkowe przydzielenie części korespondencji do marszrut najkrótszych, w rozumieniu nakładów różniczkowych $\sum_{i \in S_{k l}^{\delta}} \frac{d F\left(N_{i}[n]\right)}{d N_{i}}$ [3]. Nakłady te, stanowią podstawę mechanizmu koordynacji, kolejności rozwiązań prostych zadań poszukiwania marszrut najkrótszych, i obliczane są dla potoków rozdzielanych w iteracjach poprzednich. Nieliniowe nakłady różniczkowe, zmieniające się $\mathrm{w}$ zależności od obciążenia elementów sieci, powinny być aktualizowane jedynie dla tych elementów, które w poprzedniej iteracji zmieniały wartości potoku.

W przypadku drugim rozwiązanie optymalne uzyskuje się poprzez korektę rozkładu potoku wcześniej rozdzielonego ze względu na nakłady różniczkowe.

Wadą ukazanych dwóch podejść jest znaczące rozdzielenie potoku, co nie sprzyja operatywnemu planowaniu przewozów. W celu koncentracji potoków wykorzystamy inne podejście, oparte bezpośrednio na warunkach, określonych równaniami $(18 \div 19)$ w pracy [3].

Jego rezultatem jest sieć zrównoważona, w której poszczególne marszruty mają identyczne nakłady różniczkowe. Optymalne obciążenie wszystkich elementów sieci zapewnia stabilny rozkład pracy pomiędzy nimi, i gwarantuje maksymalne ich wykorzystanie. Dowolne odchylenie obciążenia elementów od wartości optymalnej, prowadzi do ich przeciążenia i innych, istotnych trudności w pracy sieci. Zatem, istnieje pewna zadana macierz wagonów $\left\|N_{i j}\right\|$, przy której sieć znajduje się w stanie równowagi. Obciążenie równomierne elementów sieci charakteryzuje się równością nie absolutnych $-N_{i}$ lecz względnych wartości obciążeń. Wtedy, ograniczenia progowe, dotyczące wartości potoków na łukach często okazują się mało istotnymi. Rozwiązanie zadania nieliniowego znacząco różni się od jego formy liniowej, w której potoki na łukach nie bazowych równe są zeru lub maksymalnej ich zdolności przepustowej.

Niech $\left\{N_{i}\left(S_{k l}^{\delta}\right)\right\}$ - będzie rozwiązaniem dopuszczalnym przy znaczacym rozdrobnieniu potoku. Korzystając z zależności, określonych równaniami $(18 \div 19)$ w pracy [3], rozważmy alternatywne marszruty $S_{k l}^{\delta}$ dla potoku $N_{k l}$.

Warunek lokalizacji różnych $\alpha$ części potoku $N_{k l}$ w jednej marszrucie $S_{k l}^{\delta^{*}}$ przyjmie postać:

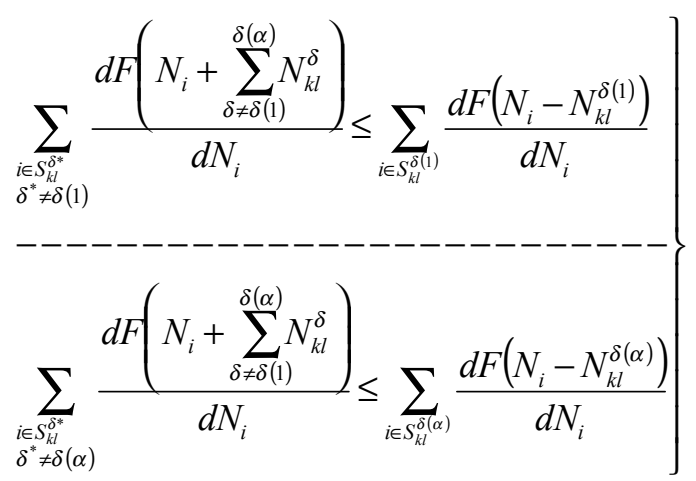

gdzie $\delta^{*}, \delta(1), \ldots, \delta(\alpha) \in\left\{1, \delta_{k l}\right\}$.

Na podstawie wyrażenia (1) można uzyskać różnorodne algorytmy minimalizacji funkcji celu (patrz równanie (1) w pracy [3]), różniące się sposobem koncentracji potoków, i wartością nakładów różniczkowych na różnych etapach marszruty. 
W szczególności, pokażemy efektywny algorytm oparty na budowie cykli kosztów ujemnych wraz z przydzielanymi do nich potokami. Rozważmy rozwiązanie dopuszczalne zadania dekompozycji, określonego równaniami $(3 \div 7) \mathrm{w}$ pracy [3].

Niech $\hat{N}_{i}$ - będzie obciążeniem $i$ - tego elementu sieci przy rozwiązaniu dopuszczalnym, $N_{k l}^{\delta}$ i $N_{k l}^{\beta}$ - to części potoku $N_{k l}$ przydzielone odpowiednio do marszruty $S_{k l}^{\delta}$ i $S_{k l}^{\beta}$. Wtedy zachodzi następująca nierówność:

$\sum_{\substack{i=S_{k=}^{s} \\ \delta \neq \beta}}\left[t_{i}\left(\hat{N}_{i}\right)+\hat{N}_{i} \frac{d t_{i}\left(\hat{N}_{i}\right)}{d N_{i}}\right]>\sum_{i \in S_{k k^{\beta}}^{s}}\left[t_{i}\left(\hat{N}_{i}\right)+\hat{N}_{i} \frac{d t_{i}\left(\hat{N}_{i}\right)}{d N_{i}}\right]$

Wyrównywanie nakładów różniczkowych dla analizowanych marszrut następuje poprzez przenoszenie wielkości $\Delta N_{k l}$ potoku $N_{k l}$, z marszruty $S_{k l}^{\delta}$ do marszruty $S_{k l}^{\beta}$. Maksymalna wielkość potoku $\Delta N_{\max }$, przenoszona $\mathrm{z}$ marszruty do marszruty wynika z warunku, określonego równaniem (19) w pracy [3], i po uwzględnieniu nierówności (2) wynosi:

$\sum_{\substack{i \in S_{\hat{k}}^{\delta} \\ \delta \neq \beta}}\left[t_{i}\left(\hat{N}_{i}-\Delta N_{\max }\right)+\left(\hat{N}_{i}-\Delta N_{\max }\right) \frac{d t_{i}\left(\hat{N}_{i}-\Delta N_{\max }\right)}{d N_{i}}\right]=$
$=\sum_{\substack{i \in S_{\beta}^{\beta} \\ \delta \neq \beta}}\left[t_{i}\left(\hat{N}_{i}+\Delta N_{\max }\right)+\left(\hat{N}_{i}+\Delta N_{\max }\right) \frac{d t_{i}\left(\hat{N}_{i}+\Delta N_{\max }\right)}{d N_{i}}\right]$

$\Delta N_{\max }$ jest jedynym, dodatnim rozwiązaniem równania (3), co wynika z nierówności (2) i charakteru zmiany prawej i lewej części tej nierówności przy zwiększaniu potoku $\Delta N_{k l}$. Jeżeli $\Delta N_{\max }>N_{k l}^{\delta}$ to potok $N_{k l}^{\delta}$ w całości przydziela się do marszruty $S_{k l}^{\beta}$, a jeśli $\Delta N_{\max }<N_{k l}^{\delta}$ to do marszruty $S_{k l}^{\beta}$ przydziela się tylko część potoku $N_{k l}^{\delta}$, równa $\Delta N_{\max }$.

Dla zapewnienia dodatniej wartości potoku, przydzielanego w każdym kroku algorytmu należy określić marszruty alternatywne, za pomocą algorytmu budowy drzewa $\alpha$ najkrótszych ścieżek.

Przedstawiona metoda wyrównywania nakładów różniczkowych posiada pewne wady wynikające z niejednoznaczności marszruty najkrótszej długości, co wpływa na przebudowę drzewa najkrótszych ścieżek. W celu eliminacji tych wad proponuje się, aby nie określać marszrut alternatywnych, tylko cykle o wadze ujemnej, które zawierają niezbędne informacje dla przegrupowania potoków.

Proponowany algorytm składa się $\mathrm{z}$ następujących kroków:

Krok 1. Przeprowadźmy ekwiwalentną zamianę wierzchołka $i$ na dwa wierzchołki $i_{1}, i_{2}$ i luk $\left(i_{1}, i_{2}\right)$. Dla rozwiązania dopuszczalnego $\left\{\hat{N}_{i}\right\}=\left\{\hat{N}_{i_{1} i_{2}}\right\}$ zbudujemy nowy rozszerzony graf $G^{\mu}$ i określimy zmodyfikowane koszty różniczkowe $F_{i_{1} i_{2}}^{\mu}$, dla wszystkich łuków:

$$
F_{i_{1} i_{2}}^{\mu}=\left\{\begin{array}{l}
\frac{d F\left(\hat{N}_{i_{1} i_{2}}\right)}{d N_{i_{1} i_{2}}}=\frac{d F\left(\hat{N}_{i}\right)}{d N_{i}}, \text { jesli } \hat{N}_{i_{1} i_{2}}>0 ; \\
-\frac{d F\left(\hat{N}_{i_{1} i_{2}}\right)}{d N_{i_{1} i_{2}}}=-\frac{d F\left(\hat{N}_{i}\right)}{d N_{i}}, \text { jesli } \hat{N}_{i_{2} i_{1}}>0 .
\end{array}\right.
$$

Krok 2. Wykorzystując zmodyfikowane koszty różniczkowe $F^{\mu}$, i stosując operacje krzyżowe [8], określamy w sieci $G^{\mu}$ cykle kosztów ujemnych $\Gamma$. Nakłady obliczeniowe w tym przypadku są takie same, jak przy poszukiwaniu najkrótszych ścieżek w sieci.

Jeżeli cyklu ujemnego nie ma, to marszruty rozwiązania dopuszczalnego $\left\{\hat{N}_{i}\right\}$ są optymalne.

Krok 3. Jeżeli cykl z kosztem ujemnym istnieje, to należy do niego dodać maksymalnie możliwy potok $\Delta N_{\max }^{\Gamma}$. Dana operacja odejmuje potoki z elementów ujemnych $\Gamma^{-}$, i dodaje te potoki do elementów dodatnich $\Gamma^{+}$cyklu $\Gamma$. Realizacja tej operacji nie zmienia wyjściowej wartości potoków, ale znacząco zmniejsza wartość funkcji celu. Cyrkulacja potoków zmienia ich wartości jedynie na łukach cyklu ujemnego, pozostawiając bez zmiany potoki na wewnętrznych łukach sieci $G^{\mu}$.

Do określenia zmniejszenia wartości funkcji celu $\Delta F\left(\Delta N^{\Gamma}\right)$, przy cyrkulacji $\Delta N^{\Gamma}$ wykorzystamy wyrażenie, określone równaniem (13) w pracy [3], które uwzględniając funkcję celu (patrz równanie (2) w pracy [3]), przyjmie postać:

$$
\Delta F\left(\Delta N^{\Gamma}\right)=\Delta N^{\Gamma}\left(\sum_{i \in \Gamma^{+}}\left(t_{i}\left(\hat{N}_{i}+\Theta \Delta N^{\Gamma}\right)\right)+\hat{N}_{i} \frac{d t_{i}\left(\hat{N}_{i}+\Theta \Delta N^{\Gamma}\right)}{d N_{i}}\right)-
$$




$$
\begin{aligned}
& -\sum_{i \in \Gamma^{\Gamma}}\left(t_{i}\left(\hat{N}_{i}-\Theta \Delta N^{\Gamma}\right)+\hat{N}_{i} \frac{d t_{i}\left(\hat{N}_{i}-\Theta \Delta N^{\Gamma}\right)}{d N_{i}}\right)+\Theta\left(\Delta N^{\Gamma}\right)^{2} . \\
& \cdot\left(\sum_{i \in \Gamma^{+}} \frac{d t_{i}\left(\hat{N}_{i}+\Theta \Delta N^{\Gamma}\right)}{d N_{i}}+\sum_{i \in \Gamma^{-}} \frac{d t_{i}\left(\hat{N}_{i}-\Theta \Delta N^{\Gamma}\right)}{d N_{i}}\right)
\end{aligned}
$$

gdzie $\Theta \in 0,1$

Niech $U_{\Gamma}$ będzie oceną cyklu ujemnego $\Gamma$, która równa jest sumie algebraicznej zmodyfikowanych kosztów różniczkowych elementów cyklu $\Gamma$. Wtedy, przy znanych strukturach funkcji wypukłych $F\left(N_{i}\right)$ największy potok w cyklu można określić z warunku $\frac{\partial(\Delta F)}{\partial(\Delta N)}=0$, lub z warunku zerowania $U_{\Gamma}$, który po uwzględnieniu zależności $(3 \div 4)$ przyjmie postać:

$$
U_{\Gamma}\left(\Delta N_{\max }^{\Gamma}\right)=\sum_{i \in \Gamma^{+}} \frac{d F\left(\hat{N}_{i}+\Delta N_{\max }^{\Gamma}\right)}{d N_{i}}-\sum_{i \in \Gamma-} \frac{d F\left(\hat{N}_{i}-\Delta N_{\max }^{\Gamma}\right)}{d N_{i}}=0
$$

$\mathrm{Z}$ równania (6) wynika, że przy $\Delta N^{\Gamma}=\Delta N_{\max }^{\Gamma}, \Delta N^{\Gamma}$ w zależności (5) w przybliżeniu staje się zerem i:

$$
\Delta F\left(\Delta N_{\max }^{\Gamma}\right) \approx \Theta\left(\Delta N_{\max }^{\Gamma}\right)^{2}\left(\sum_{i \in \Gamma^{+}} \frac{d t_{i}\left(\hat{N}_{i}+\Theta \Delta N_{\max }^{\Gamma}\right)}{d N_{i}}+\sum_{i \in \Gamma^{-}} \frac{d t_{i}\left(\hat{N}_{i}-\Theta \Delta N_{\max }^{\Gamma}\right)}{d N_{i}}\right)
$$

Określenie maksymalnego potoku $\Delta N_{\max }^{\Gamma}$ w cyklu $\Gamma$ i zmniejszenie funkcji celu $\Delta F\left(\Delta N_{\max }^{\Gamma}\right)$ można znacznie uprościć $\mathrm{w}$ przypadku liniowości zależności $t_{i}\left(N_{i}\right)$.

Niech $t_{i}\left(N_{i}\right)=a_{i} N_{i}+b_{i}$. Wtedy wyrażenie

(5) przyjmie postać:

$$
\begin{aligned}
& \Delta F\left(\Delta N^{\Gamma}\right)=\Delta N^{\Gamma}\left(\sum_{i \in \Gamma^{-}}\left(2 a_{i} N_{i}+b_{i}\right)-\sum_{i \in \Gamma^{-}}\left(2 a_{i} N_{i}+b_{i}\right)\right)+ \\
& +\left(\Delta N^{\Gamma}\right)^{2}\left(\sum_{i \in \Gamma^{+}} a_{i}+\sum_{i \in \Gamma^{-}} a_{i}\right)
\end{aligned}
$$

Potok maksymalny w cyklu $\Delta N_{\max }^{\Gamma}$ określimy $\mathrm{z}$ warunku:

$$
\begin{aligned}
& \frac{\partial \Delta F\left(\Delta N^{\Gamma}\right)}{\partial \Delta N^{\Gamma}}=\sum_{i \in \Gamma^{+}}\left(2 a_{i} N_{i}+b_{i}\right)- \\
& -\sum_{i \in \Gamma^{-}}\left(2 a_{i} N_{i}+b_{i}\right)+2\left(\Delta N^{\Gamma}\right)\left(\sum_{i \in \Gamma^{+}} a_{i}+\sum_{i \in \Gamma^{-}} a_{i}\right)=0
\end{aligned}
$$

Z zależności $(8 \div 9)$ wynika, że przy maksymalnym potoku w cyklu:

$$
\Delta N_{\max }^{\Gamma}=\frac{\sum_{i \in \Gamma^{+}}\left(2 a_{i} N_{i}+b_{i}\right)-\sum_{i \in \Gamma^{-}}\left(2 a_{i} N_{i}+b_{i}\right)}{2\left(\sum_{i \in \Gamma^{+}} a_{i}+\sum_{i \in \Gamma^{-}} a_{i}\right)}
$$

funkcja celu zmniejsza się zdecydowanie o wartość

$$
\Delta F\left(\Delta N_{\max }^{\Gamma}\right)=\left(\Delta N_{\max }^{\Gamma}\right)^{2}\left(\sum_{\Gamma^{+}} a_{i}+\sum_{\Gamma^{-}} a_{i}\right)
$$

Jeżeli sieć posiada kilka rozłącznych cykli ujemnych, to ich największy potok dodawany jest do każdego z nich.

Krok 4. Następuje korekta potoków i przejście do kroku 1, tj. określenia zmodyfikowanych kosztów różniczkowych.

W celu przeprowadzenia dowodu zbieżności algorytmu, przy liniowych zależnościach $t_{i}\left(N_{i}\right)$, przyjmiemy, $\quad$ że $\quad \sum_{\Gamma^{+}} \alpha_{i}+\sum_{\Gamma^{-}} \alpha_{i} \leq 2 a, \quad$ gdzie $a=\min _{i} a_{i} ; i=\overline{1, n}$.

Istotnie, w każdym kroku algorytmu funkcja celu maleje o wartość nie mniejszą niż $\Delta F \geq 2 a\left(\Delta N_{\max }^{\Gamma}\right)>0$, co przy uwzględnieniu dodatniej wartości funkcji nakładów $F$ i całkowitoliczbowości $\Delta N_{\max }^{\Gamma}\left(\Delta N_{\max }^{\Gamma} \geq 1\right)$ gwarantuje zbieżność algorytmu w skończonej liczbie kroków.

W przypadku nieliniowych wypukłych zależności $t_{i}\left(N_{i}\right)$, można wykorzystać dowolne metody linearyzacji.

Przy linearyzacji z wykorzystaniem stycznych charakterystyka nieliniowa $t_{i}\left(N_{i}\right)$, w dowolnie małym otoczeniu rozwiązania dopuszczalnego $\hat{N}_{i}$, aproksymowana jest styczną, czyli pochodną w danym punkcie. Linearyzacja za pomocą stycznych ma sens przy małych odchyleniach od punktu bazowego, tj. wtedy, kiedy wielkości przegrupowanych potoków są małe.

Z pracy [7] wynika, że wykresy $t_{i}\left(N_{i}\right)$ w sposób zadowalający można aproksymować cięciwami, i tym samym uprościć algorytm, przy dużych wartościach $\Delta N^{\Gamma}$. Należy podkreślić, że przy małych odchyleniach od punktu bazowego, linearyzacja poprzez cięciwy jest analogiczna do linearyzacji za pomocą stycznych.

$\mathrm{Z}$ drugiej jednak strony linearyzacja cięciwami separuje funkcjonał, określony równaniem (1) w pracy [3], i w sposób istotny upraszcza dekompozycję zadania. 
Rozważmy ten wariant aproksymacji. W tym celu podzielimy odstęp $\left[F_{i}\left(N_{i}^{1}\right) \div F_{i}\left(N_{i}^{r}\right)\right]$ punktami $N_{i}^{k}$, przy czym $N_{i}^{1}<N_{i}^{2}<\ldots<N_{i}^{r}$ i określimy dla każdego punktu $N_{i}^{k}$ wielkość $F_{i}^{k}=F_{i}\left(N_{i}^{k}\right)$, gdzie $i=\overline{1, n} ; \quad k=\overline{1, r}$. Połączymy liniami punkty $\left(N_{i}^{k}, F_{i}^{k}\right)$ i $\left(N_{i}^{k+1}, F_{i}^{k+1}\right)$ i otrzymamy odcinkami liniową aproksymację funkcji $F_{i}\left(N_{i}\right)$. Wtedy, sieć składająca się odcinkami liniowej wypukłej funkcji $\hat{F}_{i}\left(N_{i}\right)$ nakładów, odniesionych do $i$ - tego łuku można przedstawić w postaci specjalnej, zawierającej liniowe koszty łuków.

Przedstawmy każdą zmienną $N_{i}$ w postaci sumy ograniczonych, nieujemnych zmiennych $N_{k i}$, odpowiadających określonemu odcinkowi funkcji kosztów $\hat{F}_{i}\left(N_{i}\right)$, dla początkowej zmiennej $N_{i}$. Wielkości $N_{k i}$ charakteryzują zmianę zmiennej $N_{i}$ w odstępie $\left(N_{i}^{k}, N_{i}^{k+1}\right)$, przy czym $0 \leq N_{k i} \leq N_{i}^{k}-N_{i}^{k-1}$.

Wprowadzając współczynnik kosztów $\rho_{k i}$, odnoszący się do każdej nowej zmiennej $N_{k i}$, aproksymująca funkcja kosztów $\hat{F}_{i}\left(N_{i}\right)$ przyjmie postać:

$$
\hat{F}_{i}\left(N_{i}\right)=F_{i}\left(N_{i}^{1}\right)+\sum_{k=1}^{r} \rho_{k i} N_{k i}
$$

$\operatorname{gdzie} N_{i}=\sum_{k+1}^{r} N_{k i}, \quad \rho_{k i}=\frac{F_{i}^{k+1}-F_{i}^{k}}{N_{i}^{k+1}-N_{i}^{k}}$.

$\rho_{k i}$ jest tangensem kąta nachylenia liniowego odcinka aproksymującego $F_{i}\left(N_{i}\right)$ pomiędzy $N_{i}^{k}$ i $N_{i}^{k+1}$.

Uwzględniając zależność (11), wyjściową funkcją celu (patrz równanie (1) w pracy [3]), można przybliżyć następującą formą:

$$
\hat{F}^{1}=\sum_{i=1}^{n}\left(F_{i}\left(N_{i}\right)+\sum_{k=1}^{r} \rho_{k i} N_{k i}\right) \rightarrow \min
$$

Zadanie (12) łatwo dekomponuje się na skończony ciagg prostych zadań poszukiwania najkrótszych łańcuchów w specjalnie zbudowanej sieci $\hat{G}$. W sieci tej, każdej aproksymującej funkcji $\hat{F}_{i}\left(N_{i}\right)$ odpowiada zbiór $r$ łuków równoległych. Dowolny $k-$ ty łuk odnosi się do odcinka $\hat{F}_{i}\left(N_{i}\right)$ i charakteryzuje się: funkcją kosztów $\left(\rho_{k i}\right)$, zdolnością przepustową $C_{k l}=N_{i}^{k}-N_{i}^{k-1} \quad$ i nową zmienną $N_{i}^{k}$, gdzie $i=\overline{1, n} ; k=\overline{1, r}$.
Wypukłość funkcji $\hat{F}_{i}\left(N_{i}\right)$ gwarantuje monotoniczny wzrost współczynnika kosztów $\rho_{k i}$, a to oznacza, że w poszukiwaniu najkrótszych łańcuchów, przy $p<q$, zmienna $N_{p i}$ odgrywa większą rolę niż zmienna $N_{q i}$. Nim $N_{q i}$ wejdzie do zbioru rozwiązań, wcześniejsze zmienne $N_{S i}$ powinny osiagnąć możliwie maksymalną wartość.

Funkcjonowanie algorytmu wyboru marszrut polega na poszukiwaniu najkrótszych łańcuchów w specjalnej sieci $\hat{G}$ i stopniowym nasycaniu ich potokami. Przy włączaniu wierzchołka $i$ do marszruty, pierwszym z $r$ równoległych łuków incydentych $\mathrm{z}$ tym wierzchołkiem, będzie obciążony potokiem łuk o najmniejszym koszcie, zaś w przypadku wyczerpania się zdolności przepustowej, potok będzie przyłączany do kolejnego, równoległego łuku incydentnego. Wadę przedstawionego algorytmu jest istotna rozbudowa modelu, będąca efektem odcinkami-liniowej aproksymacji. Rozmiary modelu można efektywnie zmniejszać poprzez aproksymację cięciwami, w formie niejawnej i dodanie potoków w cyklach ujemnych rozszerzonego grafu $G^{\mu}$. Algorytm taki zawiera następujące kroki:

Krok 1. Przy danym rozwiązaniu dopuszczalnym $\left\{\hat{N}_{i}\right\}=\left\{\hat{N}_{i, i_{2}}\right\}$,wyliczamy maksymalną wartość przydzielanego potoku $\Delta N[1]$, który w szczegó1ności może być równy $\Delta N[1]=\max _{i j} N_{i j}$.

Dla rozwiązania dopuszczalnego $\left\{\hat{N}_{i, i_{2}}\right\} \mathrm{i}$ zadanego $\Delta N[1]$, budujemy nowy graf rozszerzony $G_{[1]}^{\mu}$ i określamy koszty zmodyfikowane $F_{i_{1} i_{2}}^{+\mu}[1]$ i $F_{i_{1} i_{2}}^{-\mu}[1]$, dla łuków obu kierunków, za pomocą aproksymacji pochodnej:

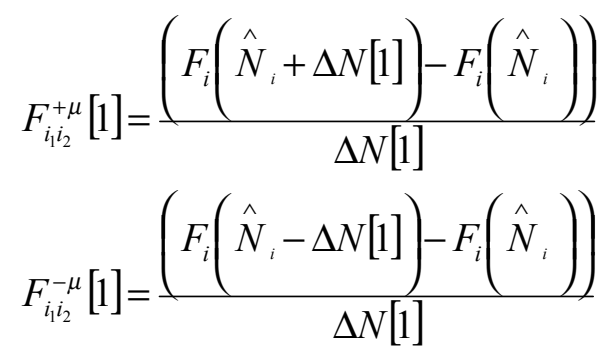

Z zależności (13) wynika, że przy określaniu kosztów zmodyfikowanych następuje niejawna aproksymacja cięciwami. 
Krok 2. W zbudowanej sieci $G_{[1]}^{\mu}$ poszukujemy cykl o wartości ujemnej. Pojawienie się cyklu ujemnego w $G_{[1]}^{\mu}$ świadczy, że „doładowanie” łuków w jednym kierunku potokiem $\Delta N[1]$,zdjętym” z łuków kierunku przeciwnego prowadzi do zmniejszenia kosztów sumarycznych.

Jeżeli przegrupowanie potoków następuje całymi relacjami, to cykle ujemne należy szukać jedynie względem, odpowiadających danemu rozwiązaniu dopuszczalnemu $\left\{\hat{N}_{i}\right\}$, marszrut przemieszczania się potoków $\max _{i, j} N_{i j}$.

Krok 3. Jeśli cykl o wartości ujemnej istnieje, to należy do niego dołączyć potok $\Delta N[1]$, przeprowadzić korektę potoków i przejść do kroku 1. Przejście do kroku 1 następuje w przypadku braku cyklu ujemnego, przy zadanym potoku $\Delta N[1]$. Przy przejściu wybiera się mniejszą wartość przegrupowanego poto$\mathrm{ku} \Delta N[2]$. Przegrupowując pełnymi relacjami potoki duże, korzystamy z następującego priorytetu:

$$
\Delta N[n]=\max _{i, j} N_{i j} \quad ; \quad \Delta N[n] \neq \Delta N[i]
$$$$
\Delta N[n]<\ldots<\Delta N[2]<\Delta N[1]
$$

gdzie $i=\overline{1, n-1}$

Jeżeli, $\Delta N=\min N_{i j}$ i brak jest cykli ujemnych, to bieżące rozdzielenie potoków jest optymalne.

Opracowując program komputerowy wyboru marszrut, dla potoków ładunków w transporcie kolejowym, należy uwzględnić:

- zdolności przepustowe szlaków i stacji;

- skalę zmian nakładów (pieniężnych i czasowych) każdego szlaku i każdej stacji, w zależności od stopnia ich wyposażenia i wielkości przerabianego potoku;

- dowolne postacie zależności nakładów od obciążeń elementów sieci kolejowej, włączając również funkcje kar;

- wybór nie tylko marszrut najkrótszych, ale również tych, które leżą w bezpośrednim ich otoczeniu;

- wybór marszrut zarówno dla potoków wagonów jak i dla potoków pociaggów, które obciążają i odciążają wybrane zbiory stacji i szlaków;

- określenie wartości odchyleń potoków dla wybranych marszrut;

- obliczenia dotyczące pełnej charakterystyki wybranej marszruty.

Danymi wejściowymi dla takiego programu powinny być informacje o: stacjach, szlakach i potokach wagonów.
Obliczenia dotyczące rozdziału potoków można prowadzić etapami, na zasadzie metod interaktywnych. Metody takie pozwalają w trybie operatywnym dokonywać korekty w obliczeniach, w zależności od wyników etapów wcześniejszych.

\section{Literatura}

[1] Акулиничев В.М. и др.: Организаџия вагонопотоков и маршрутизачия перевозок, М., «Транспорт», 1970

[2] Cisowski T.: Metodyka wyboru dróg przewozu tadunków $w$ transporcie kolejowym. Pojazdy Szynowe Nr/2008

[3] Cisowski T.: Model matematyczny wyboru optymalnych dróg przewozu tadunków $w$ transporcie kolejowym. Pojazdy Szynowe $\mathrm{Nr}$ 12008

[4] Deo N.: Teoria grafów i jej zastosowanie $w$ technice i informatyce, PWN, 1980

[5] Gajda B.: Technologia i automatyzacja pracy stacji, Wydawnictwo Politechniki Warszawskiej, 1983

[6] Gutenbaum J.: Modelowanie matematyczne systemów, PWN, Warszawa-Łódź, 1987

[7] Кутыркин А.В., Кадушин А.И.: Декомпозиционный алгоритм регулирования порожних вагонопотоков в АСУЖТ, М., «Транспорт», «Вестник ВНИИЖТ》, №6, 1978

[8] Кутьркин А.В.: Динамическая модель планирования и оперативного управления вагонопотоками, «Вестник ВНИИЖТ», №8,1981 